\title{
Chronic low back pain and physical activity among patients within the Brazilian National Health System: a cross-sectional study
}

\author{
Everton Alex Carvalho Zanuto', Rômulo Araújo Fernandes", Bruna Camilo Turi-Lynch"', Robson Chacon Castoldi"', \\ Luana Carolina de Moraisv', Pedro Victor Tonicante da Silvav", Jamile Sanches Codogno vil \\ Faculdade de Ciências e Tecnologia (FCT), Universidade Estadual Paulista (UNESP), Presidente Prudente (SP), Brazil
}

PhD. Physiotherapist/Physical Educator and Teacher, Department of Physical Education, Universidade do Oeste Paulista (UNOESTE),

Presidente Prudente (SP), Brazil.

(D) orcid.org/0000-0002-7558-1941

"PhD. Physical Educator and Teacher, Department of Physical Education and Postgraduate Physiotherapy Program, Faculdade de Ciências e Tecnologia (FCT), Universidade Estadual Paulista (UNESP), Presidente Prudente (SP), Brazil.

(D) orcid.org/0000-0003-1576-8090

"'PhD. Physical Educator, Department of Physical Education, Universidade Estadual Paulista (UNESP), Rio Claro (SP), Brazil.

(D) orcid.org/0000-0002-2803-1058

IvPhD. Physical Educator and Teacher, Department of Physical Education, Universidade do Oeste Paulista (UNOESTE), Presidente Prudente (SP), Brazil.

(D) orcid.org/0000-0002-4167-6790

vMSc. Physical Educator and Doctoral Student, Faculdade de Ciências e Tecnologia (FCT), Universidade Estadual Paulista (UNESP), Presidente Prudente (SP), Brazil. Author's Title: MSc (D) orcid.org/0000-0003-0960-4954

v'Undergraduate Student, Department of Physical Education, Universidade do Oeste Paulista (UNOESTE), Presidente Prudente (SP), Brazil. (D) orcid.org/0000-0001-5792-1239

vilPhD. Physical Educator and Teacher, Department of Physical Education and Postgraduate Physiotherapy Program, Faculdade de Ciências e Tecnologia (FCT), Universidade Estadual Paulista (UNESP), Presidente Prudente (SP), Brazil.

(D) orcid.org/0000-0003-4273-9375

KEY WORDS (MeSH terms):

Adult.

Public health.

Low back pain.

Exercise.

Risk factors.

\section{AUTHORS' KEY WORDS:}

Physical activity.

Chronic low back pain.

Alternative intervention.
BACKGROUND: This study was based on filling a gap in our knowledge regarding the issue of what the protective effect of physical exercise on patients within the Brazilian National Health System could be, in relation to low back pain.

OBJECTIVES: To determine the prevalence of chronic low back pain (CLBP) and to analyze the protective effect of physical exercise among patients over 50 years old attended at primary healthcare units (PHUs). DESIGN AND SETTING: Analytical cross-sectional study at Universidade Estadual Paulista (UNESP) that was conducted in two PHUs (Parque Cedral and Vila Real), located in different regions of the city of Presidente Prudente, Brazil.

METHODS: In total, 327 patients were interviewed and evaluated at which retrospective characteristics covering the previous 12 months. The Nordic questionnaire was used to classify CLBP, and the Baecke questionnaire for physical activity level. The body mass index $\left(\mathrm{kg} / \mathrm{m}^{2}\right)$ was calculated using body mass and height values, both collected at the time of the interview.

RESULTS: High prevalence of low back pain was found; 175 patients (53.5\%) reported having had at least one episode of low back pain in the previous year. Of these, 71 (21.7\%) answered yes to all four questions on the Nordic questionnaire and were classified as CLBP. Physical exercise remained associated with CLBP, independent of other factors (odds ratio $=0.35 ; 95 \%$ confidence interval $=0.15-0.80$ ).

CONCLUSION: High prevalence of low back pain was identified among PHU users. Physical exercise was associated as an independent protective factor against this pathological condition.

\section{INTRODUCTION}

Low back pain has been found to be highly prevalent worldwide, for example in Germany $(59 \%),{ }^{1}$ Turkey $(51 \%),{ }^{2}$ France $(55.4 \%)^{3}$ and the United States $(50 \%) .{ }^{4}$ This health impairment can evolve to motor incapacitation, thereby severely compromising the quality of life of the individuals affected. Only $15 \%$ of the cases are of known etiology, which makes treatment difficult and reduces the chances of a good prognosis. ${ }^{4}$

Occurrences of low back pain are the second largest cause of medical consultations in the world, ${ }^{4}$ and this has a significant impact on public health systems, both through direct expenditure (consultations, medications, physiotherapy and examinations) and through indirect expenditure (reduction in productivity and absenteeism). ${ }^{5}$ In the United States, the estimated cost of chronic low back pain is 100 billion dollars per year, ${ }^{6}$ while in the United Kingdom the cost of back pain reaches 480 million pounds per year.?

A large part of the adult population suffers from this disorder (50.2\%), of which $11.3 \%$ suffer from chronic low back pain. ${ }^{8}$ Consequently, low back pain leads the ranking in disability pensions (29.96 per 100,000 taxpayers). ${ }^{9}$ The following determinants of low back pain have been recognized: sex, chronological age, work condition, excess weight and sleep. ${ }^{8}$ Physical activity, although not clearly understood, seems to be a great ally in prevention of this pathological condition, especially because this is a non-pharmacological tool with low cost. ${ }^{10,11}$

Primary healthcare units (PHUs) serve the majority of the Brazilian population. They form the main triage locations for primary care, in which the focus is prevention and avoidance of the need for patients to access other levels of healthcare. Public policies need to be based on 
scientific evidence, so as to effectively meet the requirements of the community.

\section{OBJECTIVE}

The aims of the present study were to determine the prevalence of chronic low back pain and to analyze the possible protective effect of physical exercise in different domains, among patients over 50 years of age who were attended at PHUs in Presidente Prudente, Brazil.

\section{METHODS}

\section{Design and setting}

This was an analytical cross-sectional study at Universidade Estadual Paulista (UNESP) that was conducted in two PHUs (Parque Cedral and Vila Real), located in different regions of the city of Presidente Prudente, São Paulo, Brazil.

\section{Ethical issues}

This study was approved by the local Research Ethics Committee, at the Presidente Prudente campus of UNESP (procedural number: 241291; date: April 5, 2013).

\section{Sample calculation and subject selection process}

The sample was composed of adults over 50 years old, of both sexes, who were attended at two PHUs (Parque Cedral and Vila Real), which are located in different regions of the city of Presidente Prudente. This age group was chosen because individuals of this age present greater incidence of chronic low back pain. ${ }^{8}$ The PHUs involved in the study were indicated by the Health Department of Presidente Prudente. This city is located in the west of the state of São Paulo and has approximately 208,000 inhabitants and a human development index of 0.806 (which is considered high).

The minimum sample size was calculated using the prevalence of chronic low back pain (14.7\%) that was reported by Almeida et al. ${ }^{12}$ in an epidemiological study in the city of Salvador, Bahia, and a standard error of $5 \%$. These were inserted into an equation for population parameters. In addition, a population of 208,000 inhabitants was considered, with a $95 \%$ confidence interval (95\% CI) $(z=1.96)$. With the configuration described above, the equation indicated that interviews with at least 206 adults of both sexes would be needed. Lastly, $50 \%$ was added to allow for possible losses during the 12-month study period. This resulted in a need to interview 310 people, i.e. 155 patients at each BHU.

During the mornings of a 60 -day period, all patients attended at these PHUs were invited to take part in the study, if they fulfilled all of the following inclusion criteria: i) registration at that PHU for at least one year, with at least one medical consultation attended over the previous six months; ii) age > 50 years; iii) resident in the city of Presidente Prudente for at least two years; iv) signing of an informed consent statement.

At each of the two PHUs selected, an initial screening of the medical schedules of all patients who had visited the unit over the previous thirty days was performed. At each PHU, all patients seen over the previous 30 days who met the inclusion criteria were invited to participate.

The patients thus selected were invited to attend the PHU for an evaluation and directed interview. The final sample consisted of 327 patients.

\section{Evaluations}

\section{Low back pain}

The questionnaire developed by Kuorinka et al. ${ }^{13}$ and previously validated for the Portuguese language, ${ }^{14,15}$ which evaluates occurrences of musculoskeletal symptoms (pain, tingling or numbness), was used in this study but only for the lower back region. For each body region, there are four dichotomous questions (yes or no) regarding:

i. the presence of musculoskeletal disorders over the previous 12 months;

ii. impairment of daily activities over the previous 12 months, due to these disorders;

iii. consulting a healthcare professional because of these disorders; and

iv. feeling the presence of these disorders in the week immediately prior to the interview. Positive responses to these four questions were considered to be indicative of chronic low back pain in the lumbar region.

\section{Economic condition}

To determine the participants' economic situation, a questionnaire developed by the Brazilian Association of Market Research Companies (2010) was used. In this, economic situation is subdivided from $\mathrm{A}$ (highest) to $\mathrm{E}$ (lowest). The sample was subsequently dichotomized into high economic situation (categories A and B) and low economic situation (categories $\mathrm{C}, \mathrm{D}$ and $\mathrm{E}$ ), as adopted by Fernandes et al. ${ }^{16}$ The present questionnaire was applied through an interview, which was conducted by the research coordinator.

\section{Nutritional status}

Body mass index (in $\mathrm{kg} / \mathrm{m}^{2}$ ) was calculated using body mass and height values, which were both obtained at the time of the interview, in accordance with the protocol of Lohman et al. ${ }^{17}$ The presence of overweight/obesity was diagnosed when the body mass index presented values between 25 and $29.9 \mathrm{~kg} / \mathrm{m}^{2}$ for overweight and $\geq 30 \mathrm{~kg} / \mathrm{m}^{2}$ for obesity. ${ }^{18}$ 


\section{Habitual physical activity}

Information regarding habitual physical activity practices was collected by means of an interview using the questionnaire developed by Baecke et al., ${ }^{19}$ which was translated and validated for Brazilian realities by Florindo et al. ${ }^{20}$ Through application of the instrument, it was possible to identify the level of habitual physical activity in each domain. The sum of the scores for each section gave the total score, i.e. habitual physical activity. For the purpose of statistical analysis, the sample was subdivided into quartiles according to the total physical activity score from the instrument (which analyzes three domains of physical activity: i- occupational; ii- physical exercise during leisure; iii- leisure and locomotion). Participants in the $75^{\text {th }}$ percentile and above (highest quartile) were considered physically active. Cycling was also computed dichotomously (yes or no).

\section{Confounding factors}

The following were considered to be confounding factors: education ([i] 1-4 years; [ii] 5-8 years; [iii] 9-11 years; or [iv] $\geq 12$ years); gender (male or female); age ( $<65$ years or $\geq 65$ years); ethnicity (white, black or other color); and current occupational activity (yes or no).

\section{Statistical procedures}

Numerical variables were presented as means and standard deviations, and the means were compared using Student's $t$ test. Categorical variables were expressed as absolute and percentage values, and univariate statistical tests were applied to these $\left(\chi^{2}\right.$, with the Yates correction applied via $2 \times 2$ contingency tables). When significant differences were found, the values were inserted in a multivariate model (binary logistic regression) with hierarchical insertion. The magnitude of associations was expressed in terms of odds ratio (OR) values and their respective 95\% confidence interval (CI). In our analysis model, associations between the dependent variable (chronic low back pain) and the independent variables were investigated, and the results were corrected for possible confounding variables (sex, economic situation, adiposity and age). The statistical analyses were performed using specific software (BioEstat version 5.0) and, in all procedures, the significance level adopted was $5 \%$.

\section{RESULTS}

The sample was composed of 327 patients, i.e. 229 females (70\%) and 98 males (30\%). The mean body mass index was $29.1 \pm 5.4 \mathrm{~kg} / \mathrm{m}^{2}$, the mean age was $62 \pm 8.8$ years and 83 patients $(25.4 \%)$ had a current occupation. Low back pain was found to be present in 175 patients (53.5\%), i.e. at least one episode of low back pain in the previous year. Among these patients with low back pain, 71 (21.7\%) gave positive responses to the four questions about low back pain and were therefore classified as having chronic low back pain. Females had higher odds of developing chronic low back pain $(\mathrm{OR}=2.63$; 95\% CI $=1.24-1.55)$. The independent variables are presented in Table 1, thus characterizing the sample and the influence of these variables on the outcome of chronic low back pain.

In the whole sample, 78 patients (23.9\%) were considered physically active. The variables associated with chronic low back pain were inserted into the binary logistic regression, which resulted in the odds ratios presented in Table 2.

Table 1. General characteristics of the sample

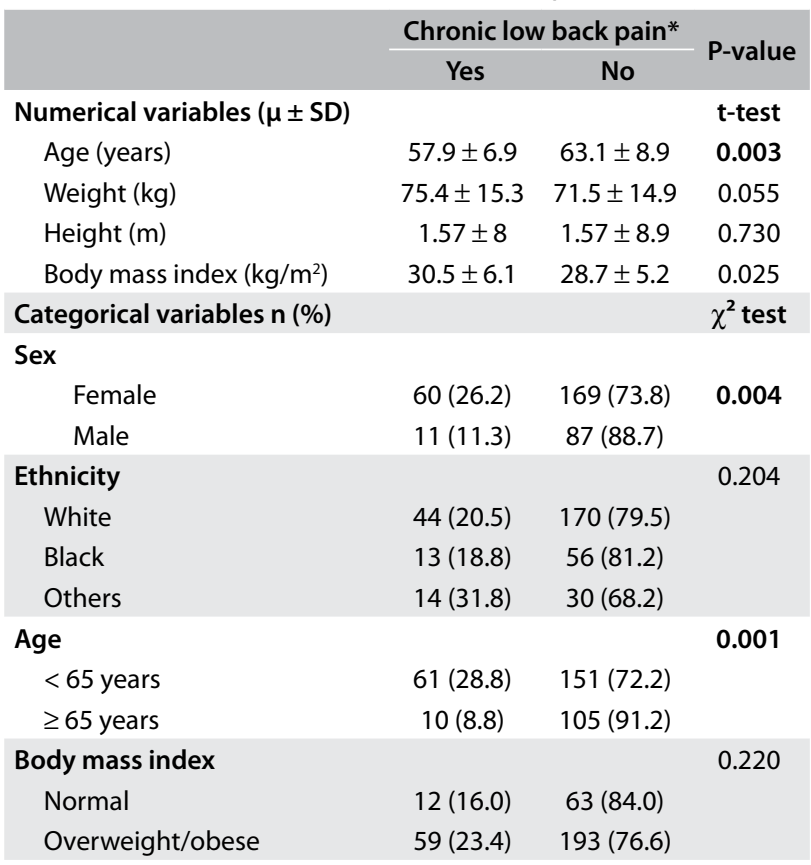

*Positive responses to the four questions in the questionnaire; $\mu \pm S D=$ mean and standard deviation.

Table 2. Factors associated with chronic low back pain among Brazilian primary healthcare unit patients

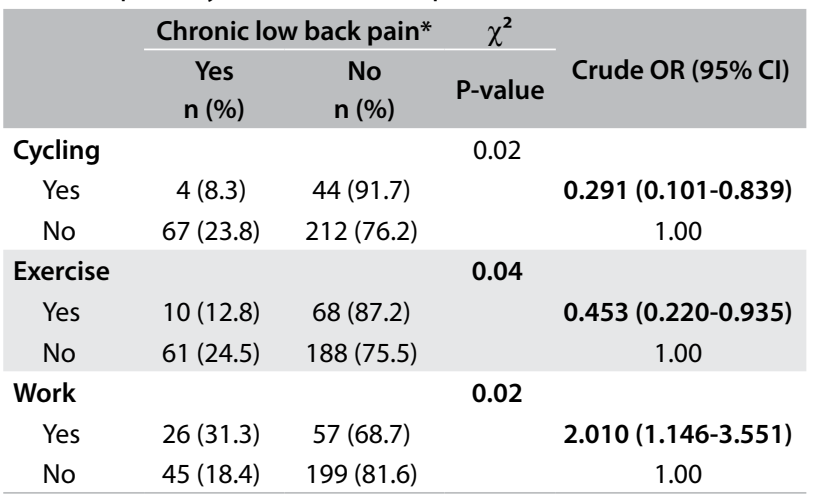

*Positive responses to the four questions in the questionnaire; $\mathrm{OR}=$ odds ratio; $95 \% \mathrm{Cl}=95 \%$ confidence interval. 
The variables that were associated with chronic low back pain, as shown in Table 2, were inserted hierarchically in multivariate models, as demonstrated in Table 3 , to test whether these associations were independent of the other factors.

\section{DISCUSSION}

The prevalence of low back pain found in the present study (53.5\%) is similar to that reported from another survey carried out in the same city $(50.2 \%),{ }^{8}$ and also to reports from other studies around the world. ${ }^{1-4}$ However, the prevalence of chronic low back pain, of $21.7 \%$, was higher than what had been found in other studies conducted in Brazil: in the states of Bahia $(14.7 \%)^{12}$ and São Paulo $(11.3 \%)^{8}$. It is possible this difference is due to the fact that these other studies were population-based studies, thus differing from the characteristics of the population of the present study, which comprised PHU patients. Another important factor that contributed towards higher prevalence of low back pain was the age group evaluated in the present study, i.e. individuals over 50 years old. This differs from population studies, which encompass all adults over the age of 18 years. This important observation reflects the need for prophylactic measures and/or specific treatments to control this pathological condition. This need is not exclusive to the present study.

In the models created, female sex was shown to be a risk factor for the development of chronic low back pain, independently of the other confounding factors $(\mathrm{OR}=2.63 ; 95 \% \mathrm{CI}=1.24-1.55)$. This greater occurrence may have been due to anatomical-functional

Table 3. Model adjusted for association between chronic low back pain and independent variables

\begin{tabular}{|c|c|c|c|}
\hline & Model 1 & Model 2* & Model $3 * *$ \\
\hline & OR $(95 \% \mathrm{Cl})$ & OR $(95 \% \mathrm{Cl})$ & OR $(95 \% \mathrm{Cl})$ \\
\hline \multicolumn{4}{|c|}{ Cycling } \\
\hline Yes & $\begin{array}{c}0.284 \\
(0.094-0.861)\end{array}$ & $\begin{array}{c}0.283 \\
(0.093-0.859)\end{array}$ & $\begin{array}{c}0.378 \\
(0.122-1.167)\end{array}$ \\
\hline No & $\begin{array}{c}1.00 \\
\text { (Reference) }\end{array}$ & $\begin{array}{c}1.00 \\
\text { (Reference) }\end{array}$ & $\begin{array}{c}1.00 \\
\text { (Reference) }\end{array}$ \\
\hline \multicolumn{4}{|c|}{ Physical exercise } \\
\hline Yes & $\begin{array}{c}0.390 \\
(0.182-0.836)\end{array}$ & $\begin{array}{c}0.388 \\
(0.181-0.831)\end{array}$ & $\begin{array}{c}0.356 \\
(0.159-0.800)\end{array}$ \\
\hline No & $\begin{array}{c}1.00 \\
\text { (Reference) }\end{array}$ & $\begin{array}{c}1.00 \\
\text { (Reference) }\end{array}$ & $\begin{array}{c}1.00 \\
\text { (Reference) }\end{array}$ \\
\hline \multicolumn{4}{|l|}{ Work } \\
\hline Yes & $\begin{array}{c}1.308 \\
(0.715-2.393)\end{array}$ & $\begin{array}{c}1.302 \\
(0.711-2.382)\end{array}$ & $\begin{array}{c}1.181 \\
(0.628-2.220)\end{array}$ \\
\hline No & $\begin{array}{c}1.00 \\
\text { (Reference) }\end{array}$ & $\begin{array}{c}1.00 \\
\text { (Reference) }\end{array}$ & $\begin{array}{c}1.00 \\
\text { (Reference) }\end{array}$ \\
\hline
\end{tabular}

$\mathrm{OR}=$ odds ratio; $95 \% \mathrm{Cl}=95 \%$ confidence interval; yes $\geq 75^{\text {th }}$ percentile; no $<75^{\text {th }}$ percentile; Model 1: model adjusted according to socioeconomic variables (sex, age, ethnicity and economic situation); Model 2: model adjusted according to socioeconomic variables and body mass index; ${ }^{*}$ Hosmer and Lemeshow test with P-value $=0.544$; Model 3 : all variables inserted; ${ }^{*}$ Hosmer and Lemeshow test with P-value $=0.061$. differences, but may also have come from women's double working day. ${ }^{8}$ Sex lost statistical significance only when physical and occupational activities were inserted in the model. Culturally, in Brazil, men are more active during leisure time than women, ${ }^{16}$ and this would be a protective factor against chronic low back pain. On the other hand, men perform functions with greater physical overloads, which increases the risk of developing chronic low back pain. ${ }^{3}$ This factor may be the explanation for the loss of significance when the data were adjusted for these variables.

Patients who reported that they were working also presented greater risk of developing chronic low back pain $(\mathrm{OR}=2.01$; $95 \% \mathrm{CI}=1.14-3.55)$. This association lost significance when inserted into the multivariate model together with age and economic situation, perhaps because people in a higher economic situation have better information about healthy life habits and also do not need to work when they have reached this age group. ${ }^{1}$

It is known that workers in several types of occupation perform functions that contribute towards installation of this pathological condition. Moreover, chronic low back pain can cause decreased productivity and quality of life among the individuals affected, and this may lead to susceptibility to absences from work. It is therefore important to stress that management teams in public institutions and other employers need to make efforts to prevent and/or combat this important health problem. .,22,23 $^{2}$

Encouragement to practice physical activity may be a strategy, through advertisements that incorporate healthy values and increase the level of physical activity. In Brazil, the example of the United States could be adopted, with a national road map to improve the quality of health through a physically active lifestyle, like the one developed by the American College of Sports Medicine, which involves four steps: awareness, education, partnerships and monitoring. ${ }^{24}$

The physical activity practices among PHU users seem to be a relevant problem, since only $24 \%$ of the interviewees were classified as sufficiently active. This is a low percentage and is similar to that reported by Turi et al..$^{25}$ in the city of Bauru, also among PHU patients (24.9\%). In Brazil, promotion of physical activity only began widely in the 1970 s.

Promotion of physical activity has greater efficacy among younger individuals. Moreover, if physical activity practices are insufficient during youth, this tends to continue into adulthood, since the characteristics of these practices tend to stabilize over time. ${ }^{26,27}$ Given that the population of this study was older than 50 years, the participants had probably not been given as much encouragement as young people currently are, which will have led to higher rates of sedentary behavior among people who are now over 50 years of age. ${ }^{28}$

Lastly, the greatest contribution of the present study was to make a correlation between the level of physical activity and occurrences of chronic low back pain. Physically active people were found to 
have $65 \%$ less chance of developing chronic low back pain, independently of other factors. This differed from some previous studies, in which physical activity lost its association when inserted in the multivariate model. ${ }^{8,12}$ However, the current findings corroborate those of other studies, in which the benefits of being physically active on this disorder were demonstrated. ${ }^{1,22,23}$ This validates the practice of physical activity and makes it an important option in relation to prevention and/or treatment of this disorder.

The beneficial effects of regular physical activity on maintenance of good health have been recognized worldwide. ${ }^{24,28}$ In relation to chronic low back pain, these effects are no different: physical activity plays a fundamental role, indirectly or directly, in the preventive aspects of reducing the risks of developing this pathological condition.

There is evidence indicating that physically active people are less likely to develop poor sleep quality. Poorer sleep quality has been correlated with chronic low back pain. ${ }^{8}$ Another indirect benefit of physical activity to reduce the risks of developing chronic low back pain is in controlling obesity. ${ }^{8,11,13}$ Systematized general physical exercise programs of both low and moderate intensities are considered to be directly protective against chronic low back pain, and are applied in treating this disorder. ${ }^{11}$

It is worth highlighting the methodological design of the present study. It used a sample of the population that was of significant size and demonstrated that physical activity was a protection factor in different domains of leisure and locomotion, in relation to chronic low back pain. Thus, public policies aimed towards increasing the level of physical activity should be encouraged, such as inclusion of physical educators and training infrastructure within PHUs.

However, there were some limitations to the present study. The lack of a more sophisticated method for diagnosing low back pain, the reverse causality bias applied in this study and the data collection method used (active charts alone), which led to a large discrepancy in the numbers of men and women in the sample, should be considered to be the main limitations. These form directions for future studies.

\section{CONCLUSION}

A high prevalence of low back pain was identified among PHU patients, while the practice of physical exercise during leisure time was a protective factor against this outcome.

\section{REFERENCES}

1. Schneider S, Mohnen SM, Schiltenwolf SM, Rau C. Comorbidity of low back pain: representative outcome of a national health study in the Federal Republic of Germany. Eur J Pain. 2007;1 1(4):387-97. PMID: 16793296; doi: 10.1016/j.ejpain.2006.05.005.

2. Altinel $L$, Köse KC, Ergan $V$, et al. The prevalence of low back pain and risk factors among adult population in Afyon region, Turkey. Acta Orthop
Traumatol Turc. 2008;42(5):328-33. PMID: 19158453; doi: 10.3944/ aott.2008.328.

3. Leclerc A, Gourmelen J, Chastang JF, et al. Level of education and back pain in France: the role of demographic, lifestyle and physical work factors. Int Arch Occup Environ Health. 2009;82(5):643-52. PMID: 18956210; doi: 10.1007/s00420-008-0375-4.

4. Srinivas SV, Deyo RA, Berger ZD. Application of "less is more" to low back pain. Arch Intern Med. 2012;172(13):1016-20. PMID: 22664775; doi: 10.1001/archinternmed.2012.1838.

5. Dagenais S, Caro J, Haldeman S. A systematic review of low back pain cost of illness studies in the United States and internationally. Spine J. 2008;8(1):8-20. PMID: 18164449; doi: 10.1016/j.spinee.2007.10.005.

6. McCarberg BH, Billington R. Consequences of neuropathic pain: quality-of-life issues and associated costs. Am J Manag Care. 2006;12(9 Suppl):S263-8. PMID: 16774458.

7. Clinical Standards Advisory Group. Epidemiology review: the epidemiology and cost of back pain. Soc Sci Med. 1996;42(4):561-63.

8. Zanuto EAC, Codogno JS, Christófaro DGD, et al. Prevalence of low back pain and associated factors in adults from a middle-size Brazilian city. Ciênc Saúde Coletiva. 2015;20(5):1575-82. doi: 10.1590/141381232015205.02162014.

9. Meziat-Filho N, Silva GA. Invalidez por dor nas costas entre segurados da Previdência Social do Brasil [Disability pension from back pain among social security beneficiaries, Brazil]. Rev Saude Publica. 2011;45(3):494502. doi: 10.1590/s0034-89102011000300007.

10. Ferreira MC, Penido H, Aun A, et al. Eficácia dos exercícios de controle motor na dor lombopélvica: uma revisão sistemática [Efficacy of motor control exercises for lumbopelvic pain; a systematic review]. Fisioter Pesqui. 2009;16(4):374-9. Available from: http://www.scielo.br/pdf/fp/ v16n4/16.pdf. Accessed in 2019 (Sep 24).

11. Burton AK, Balagué F, Cardon G, et al. Chapter 2. European guidelines for prevention in low back pain: November 2004. Eur Spine J. 2006;15 Suppl 2:S136-68. PMID: 16550446; doi: 10.1007/s00586-006-1070-3.

12. Almeida ICGB, Sá KN, Silva M, et al. Prevalência de dor lombar crônica na população da cidade de Salvador [Chronic low back pain prevalence in the population of the city of Salvador]. Rev Bras Ortop. 2008;43(3):96102. doi: 10.1590/S0102-36162008000200007.

13. Kuorinka I, Jonsson B, Kilbom A, et al. Standardised Nordic questionnaires for the analysis of musculoskeletal symptoms. Appl Ergon. 1987;18(3):233-7. PMID: 15676628; doi: 10.1016/0003-6870(87)90010-x.

14. Pinheiro FA, Troccoli BT, Carvalho CV. Validação do Questionário Nórdico de Sintomas Osteomusculares como medida de morbidade [Validity of the Nordic Musculoskeletal Questionnaire as morbidity measurement tool]. Rev Saude Publica. 2002;36(3):307-12. PMID: 12131969; doi: 10.1590/s0034-89102002000300008

15. de Barros EN, Alexandre NM. Cross-cultural adaptation of the Nordic musculoskeletal questionnaire. Int Nurs Rev. 2003;50(2):101-8. PMID: 12752909; doi: 10.1046/j.1466-7657.2003.00188.x. 
16. Fernandes RA, Zanesco A. Early physical activity promotes lower prevalence of chronic diseases in adulthood. Hypertens Res. 2010;33(9):926-31. PMID: 20574424; doi: 10.1038/hr.2010.106.

17. Lohman TG, Roche AF, Martorell R. Anthropometric Standardization Reference Manual. Champaign, IL: HumanKinetics Books; 1988.

18. Organização Mundial De Saúde. Obesity, Preventing and Managing the Global Epidemic: Report of the WHO Consultation on Obesity. Geneva: World Health Organization; 1998.

19. Baecke JA, Burema J, Frijters JE. A short questionnaire for the measurement of habitual physical activity in epidemiological studies. Am J Clin Nutr. 1982;36(5):936-42. PMID: 7137077; doi: 10.1093/ ajcn/36.5.936.

20. Florindo AA, Latorre M do R, Jaime PC, Tanaka T, Zerbini CA. Methodology to evaluation the habitual physical activity in men aged 50 years or more. Rev Saude Publica. 2004;38(2):307-14. PMID: 15122389; doi: 10.1590/s0034-89102004000200022.

21. Silva MC, Fassa ACG, Valle NCJ. Dor lombar crônica em uma população adulta do Sul do Brasil: prevalência e fatores associados [Chronic low back pain in a Southern Brazilian adult population: prevalence and associated factors]. Cad Saude Publica. 2004;20(2):377-85. Available from: http://www.scielo.br/pdf/csp/v20n2/05.pdf. Accessed in 2019 (Sep 24).

22. Deyo RA, Mirza SK, Martin BI. Back pain prevalence and visit rates: estimates from U.S. national surveys, 2002. Spine (Phila Pa 1976). 2006;31 (23):27247. PMID: 17077742 ; doi: 10.1097/01.brs.0000244618.06877.cd.

23. Andersson GB. Epidemiological features of chronic low-back pain. Lancet. 1999;354(9178):581-5. PMID: 10470716; doi: 10.1016/S01406736(99)01312-4.

24. Hasson RE, Brown DR, Dorn J, et al. Achieving Equity in Physical Activity Participation: ACSM Experience and Next Steps. Med Sci Sports Exerc. 2017;49(4):848-58. PMID: 27870795; doi: 10.1249/ MSS.0000000000001161.

25. Turi BC, Codogno JS, Fernandes RA, Monteiro HL. Prática de atividade física, adiposidade corporal e hipertensão em usuários do Sistema Único de Saúde [Physical activity, adiposity and hypertension among patients of public healthcare system]. Rev Bras Epidemiol. 2014;17(4):925-37. doi: 10.1590/1809-4503201400040011.

26. Azevedo MR, Araújo CL, Cozzensa da Silva M, Hallal PC. Tracking of physical activity from adolescence to adulthood: a population-based study. Rev Saude Publica. 2007;41 (1):69-75. PMID: 17273636; doi: 10.1590/s0034-89102007000100010.
27. Gonçalves H, Hallal PC, Amorim TC, Araújo CL, Menezes AM. Sociocultural factors and physical activity level in early adolescence. Rev Panam Salud Publica. 2007;22(4):246-53. PMID: 18078586; doi: 10.1590/s102049892007000900004.

28. Fernandes RA, Zanesco A. Early sport practice is related to lower prevalence of cardiovascular and metabolic outcomes in adults independently of overweight and current physical activity. Medicina (Kaunas). 2015;51(6):336-42. PMID: 26739675; doi: 10.1016/j. medici.2015.10.003.

Authors' contributions: Zanuto EAC: conceptualization of the study, data collection, data analysis, writing and revision of the article; Fernandes RA: conceptualization of the study, data collection, data analysis, writing and revision of the article; Turi BC: conceptualization of the study, data collection, writing and revision of the article; Castoldi RC: data collection, data analysis, writing and revision of the article; Morais LC: data collection, writing and revision of the article and intellectual conceptualization of the study; Tonicante PVS: data collection, data analysis, writing and review of the article; and Codogno JS: Data collection, writing of the article, statistical analysis, intellectual conceptualization of the study and preparation of the entire research project. All the authors approved the final version and agree to be accountable for all aspects of the work, so as to ensure questions relating to the accuracy or integrity of any part of the work are appropriately investigated and resolved

\section{Sources of funding: None \\ Conflict of interest: None}

Date of first submission: September 1, 2019

Last received: November 8, 2019

Accepted: November 19, 2019

\author{
Address for correspondence: \\ Pedro Victor Tonicante da Silva \\ Rodovia Raposo Tavares, km 572 \\ Bairro Limoeiro — Presidente Prudente (SP) — Brasil \\ CEP 19067-175 \\ Tel. 0800-771-5533 \\ E-mail: pedro_tonicante@hotmail.com
}

